Ankara Să̆lık Hizmetleri Dergisi,

Cilt 15, Sayı 2, 2016

\title{
Bilişsel Rezerv ve Yaşlanan Beyin ${ }^{1}$
}

\author{
Çevirenler: Gülbahar Baştuğำ, E. Tuğba Özel-Kızı1² \\ ${ }^{1}$ Ankara Üniversitesi Sağlık Hizmetleri Meslek Yüksek Okulu \\ ${ }^{2}$ Ankara Üniversitesi Tıp Fakültesi Psikiyatri Anabilim Dalı Geropsikiyatri Birimi
}

Beyin travmasına karşı rezerv kuramı beyindeki patolojiye rağmen klinik olarak işlev görmeye devam eden bireyleri açıklamak için ortaya atılmış bir kuramdır (Gertz ve ark., 1996; Davis ve ark., 1999; Gold ve ark., 2000; Jelinger, 2000; Riley ve ark., 2002). İlk örnek olarak, bilişsel açıdan normal 10 yaşlı kadının otopside beyinlerinde Alzheimer plakları olduğunu bulmuşlardır (Katzman ve ark., 1988). Kadınların beyinleri daha ağır olup patolojiye rağmen işlevselliklerine yardım etmede "rezerv" sağladığı düşünülen çok sayıda nöron içermekteydi. Daha sonraki çalışmalar da, uzunlamasına yapılan değerlendirmeler boyunca, bilişsel açıdan normal olarak değerlendirilen deneklerin \%25-67'sinin otopside demans kriterlerini karşıladığını bulmuşlardır (Crystal ve ark., 1988; Morris ve ark., 1996; Price ve Morris, 1999; Ince, 2001; Mortimer ve ark., 2003).

Beyin travmasından sonra işlevselliği sürdürmeye katkıda bulunan iki tür rezerv vardır: beyin rezervi ve bilişsel rezerv. Beyin rezervi beynin ölçüsü (Katzman, 1993) ve/veya nöron sayısını (Mortimer ve ark., 1981) içerir. Patoloji açısından, çok fazla beyin rezervi daha iyi işlevsellik ile ilişkilidir (Satz, 1993; Graves ve ark., 1996; Jenkins ve ark. 2000). Beyin rezervi modeli işlevsel sorunların görünür olduğu bir eşik varsaymakta ve daha fazla beyin rezervi olan bireylerin o eşiğe ulaşmadan önce daha fazla patoloji biriktireceklerini ileri sürer. Örneğin, Alzheimer durumunda hastalık daha uzun zamanda ilerleyecektir ve daha çok nöron ya da daha büyük beyinle başlayan bireylerde defisitler görülmeden önce ilave patoloji elde edilecektir.

İlk beyin rezerv modeli tamamen sayısaldı: belli bir beyin hasarı her bireyi aynı biçimde etkiler ve yaşam boyunca beyin hasarları birikir. Kanıtlar bazı beyin defisitlerinin yaşam boyunca biriktiğini göstermektedir. Örneğin, Alzheimer riski her psikiyatrik epizod (Kessing ve Andersen, 2004) ile ya da beyin sarsıntısıyla (Guskiewicz ve ark., 2005) artar. Bu modelin sınırlılığı, üst üste gelen hasar işlevsel bozukluklar için gerekli eşiğe ulaşsın ya da ulaşmasın, beyin rezervinin bireyler arasında yalnızca anlamlı farklar oluşturduğunun düşünülmesidir.

Beyin rezervi modeli bazı gözlemleri açıklasa da çoğunun iyi olduğu genellemesi oldukça basit kalabilir. Örneğin, otizm daha büyük glia/nöron oranı (Redcay ve Courchesne, 2005) ya da kullanılmayan ya da hatalı nöral bağlantılarını elimine eden budama mekanizmalarının kaybını yansıtan, normalden daha büyük bir beyinle birliktedir. Üstelik de sağlıklı çocuklar, genç yetişkinler ve yaşlı örneklemlerinde daha fazla gri madde daha kötü bellek performansı ile birliktedir (Salat ve ark., 2002; Van Petten, 2004). Bu durum daha büyük beyni olanların daha büyük avantajları olmadığını ifade eder. Bu modelin başka bir sınırlılığı da Alzheimer tanısı konduğunda daha yüksek IQ ve daha fazla eğitimin daha hızlı deteriorasyon ve daha hızlı ölümle birlikte olduğu şeklindeki mantıksız bulguyu açıklamaz (Stern ve ark., 1994; Stern ve ark., 1995; Teri ve ark., 1995; Stern ve ark., 1999; Scarmeas ve ark., 2006; Hall ve ark., 2007; Helzner ve ark., 2007).

Aksine, bilişsel rezerv görevleri yerine getirirken mevcut beyin rezervini esnek ve etkili kullandırma yeteneğini anlatır (Stern, 2002). Bilişsel rezerv, okur yazar olma (Manly ve ark., 2003; Manly ve ark., 2005), mesleğin karmaşıklığı (Stern ve ark., 1994; Richards ve Sacker, 2003; Staff ve ark., 2004), boş zaman etkinliklerine kat1lım (Scarmeas ve ark., 2001; Wilson ve ark., 2002; Scarmeas ve ark., 2003a) ve sosyal ağlara bağlllık (Fratiglioni ve ark., 2000; Bernett ve ark., 2006) gibi başka değişkenler kullanılsa da, en s1k eğitim (Stern ve ark., 1992) ve IQ'yu (Alexander ve ark., 1997) kullanarak tahmin edilmektedir. Son zamanlarda kişilik değişkenleri de dahil edilmiştir (Wilson ve ark., 2006; Wilson ve ark., 2007). Daha yüksek bilişsel rezervi olanlar herhangi bir patoloji ve beyin rezervi düzeyi için daha iyi klinik sonuçlara sahip olma eğilimindedirler.

${ }^{1}$ Anil K. Nair ve Marvan N. Sabbagh'ın editörlüğünü yaptığı “Geriatric Neurology” kitabının (2014, John Wiley and Sons 1. Baskı) Adrienne M. Tucker ve Yaakov Stern tarafından yazılmış 5. Bölümü 
Mortimer ve ark. (2003) daha küçük beyin rezervi olanların (kafa çevresi ölçülerek) artmış Alzheimer riski altında olduklarını bulmuştur. Ancak bu ilişki, yani kafası daha küçük ve eğitimi daha yüksek olanların artmış risk altında olmadıkları şeklinde, bilişsel rezerv tarafından aracılık edilir. Bilişsel rezerv bireylere mevcut beyin rezervlerini daha optimal kullanmalarını sağlayarak daha küçük beyinlerindeki herhangi bir mevcut patolojiyi ödünlemelerine imkan verir. İşlevselliği sürdürmek için gerekli beyin rezervinin eşiği sabit değildir, insanlar arasında değiş̧ir, bilişsel rezervi daha yüksek olanlar daha düşük beyin rezerv düzeylerinde işlevselliği sürdürebilirler.

Bilişsel rezerv en çok Alzheimer hastalığı ve normal yaşlanma bağlamında tartışılsa da, vasküler hasar (Dufouil ve ark., 2003; Elkins ve ark., 2006), Parkinson hastalığ1 (Glatt ve ark., 1996), travmatik beyin hasarı (Kesler ve ark., 2003), HIV (Farinpour ve ark., 2003) ve multipl sklerozda (Sumowski ve ark., 2009) yarar sağladığı gösterilmiştir. Bilişsel rezervin bilişsel sonuçlar için beyin hasarına karş1 koruyucu olduğu farklı durumlarda gösterilmişken, duygulanım ya da psikiyatrik durumlar için benzer biçimde koruyucu olup olmadığı bilinmemektedir. Bir raporda Alzheimer'ın erken evresinde artan depresif belirtilere karşı bilişsel rezervin koruyucu olmadığ bulunmuştur (Geerlingss ve ark., 2000); ancak sağlıklı bireylerde daha yüksek bilişsel rezervin depresyon gibi psikiyatrik hastalığa karşı koruduğu bulunmuştur (Barnett ve ark., 2006; Koenen ve ark., 2009).

Bilişsel rezervin pek çok yanı birbiriyle bağlantılıdır. Örneğin, yüksek IQ'lu insanlar daha fazla eğitimli olurlar, dolayısıyla IQ artar (Ceci, 1991). Ancak birbiriyle bağlantılı olmalarına rağmen, bilişsel rezervin bu yanları yaşam boyunca artan hem bağımsız hem de interaktif etkiyi açılar. Richard ve Sacker (2003) yaşam boyunca farklı noktalarda biriken bilişsel rezerv değişkenlerinin orta yaşta bilişsel işlevi nasıl etkilediğini incelemişlerdir. En erken nokta yani çocukluk IQ'sunun en güçlü etkiye sahip olduğunu; daha sonraki noktanın yani erken yetişkinliğe kadar eğitim elde etmenin daha az etkisi olduğunu ve en son noktanın yani orta yaştaki mesleğin en az güçlü etkiye sahip olduğunu bulmuşlardır. Erken çocukluk faktörleri bilişsel rezervin artışı için can alıcı öneme sahip olurken, bilişsel rezerv yaşam boyunca koşullardan etkilenmeye devam eder.

Eğitim gibi bilişsel rezervi ölçmek için kullanılan değişkenlerin çoğu sosyoekonomik düzey (SED) ile ilişkilidir. Ancak Karp ve ark. (2004) daha az eğitim ve daha düşük SED daha yüksek Alzheimer hastalığı riski ile bağımsız biçimde ilişkiliyken tek başına eğitim anlamlıdır. Böylece, yüksek eğitimli olanlarda daha düşük Alzheimer hastalığı riski SED tarafından aracılık edilmez. Turnell ve ark. (2002) daha fazla eğitim yılı ve orta yaşta daha iyi bilişsel sonuçlar arasındaki ilişki hem çocukluk hem de şimdiki SED'den bağımsızdır. Böylece, bilişsel rezervden doğan yararlar SED’e indirgenemez.

Başka bir potansiyel sınırlılık ise, daha fazla eğitimi ve daha yüksek IQ'su olan bireyler bilişsel gerilemeyi ölçmek ve demans tanısı koymak için kullanılan testlerde üstün performans gösterirler, buna araştırma yanlılığı denir (Tuokko ve ark., 2003). Diğer bir deyişle, bilişsel rezervi yüksek bir birey patoloji ya da yaşlanmanın bir sonucu olarak önceki yüksek performans düzeyinden düşebilir, bu deteriorasyon test sırasında fark edilmeyebilir, çünkü performans hala ortalama düzeyde olabilir. Ancak demans tanısı nöropsikolojik testler yerine günlük işlevsellik ölçümleri ile konulduğunda, bilişsel rezerv hala yarar sağlar (Liao ve ark., 2005). Üstelik, her deneğin performansını değerlendirmek için belli bir temel ile birlikte uzunlamasına çalışmalarda da bilişsel rezerv gösterilmiştir (Scarmeas ve Stern, 2004).

Beyin rezervinin aksine, bilişsel rezerv daha yüksek IQ'lu, eğitimli, daha fazla boş zaman aktivitelerine katılanların niçin daha kötü sonuçlara sahip olduklarını ve Alzheimer hastalığı tanısından kısa süre sonra öldüklerini açıklar (Stern ve ark., 1994; Stern ve ark., 1995; Teri ve ark., 1995; Stern ve ark., 1999; Scarmeas ve ark., 2006; Hall ve ark., 2007; Helzmer ve ark., 2007) . Bilişsel rezerv modeli daha fazla rezervi olanların Alzheimer hastalığının gidișinde erken patolojiyi kompanse edebildiklerini ileri sürer. Patoloji daha fazla ilerlemeden ve hasta ölüme daha yakın olmadan bilişsel rezervi yüksek bir bireyde bozukluklar gözlenebilir. Bu şu demektir rezervi yüksek olanlar daha fazla patolojiye sahip olacaklardır (Bennett ve ark., 2003; Bennett ve ark., 2005; Serra ve ark., 2011).

Beyin rezervinin ilk kavramsallaşması tamamen sayısal iken yakın zamandaki kanıtlar bu kavramın daha çok incelikli olduğunu ileri sürmektedir. İlkin, beyin ve bilişsel rezerv bazı örtüşmeleri paylaşır. Örneğin, IQ ve beyin hacmi küçük, fakat anlamlı korelasyon gösterirler (McDaniel, 2005). Daha önemlisi, uyarıcı çevreler -mesleki beceriler ve boş zaman etkinlikleri ile meşgul olma gibi 
değişkenlerle ölçülen bilişsel rezerv unsuru- yeni nöronların gelişmesini güçlendirir (Churchill ve ark., 2002), beyin türevli nörotrofik faktörü (BDNF) upregule eder, BDNF nöral plastisiteyi güçlendirir. Üstelik, hayvan çalışmaları zenginleştirici çevrelerin Alzheimer patolojisini doğrudan azaltabildiğini öne sürer (Costa ve ark., 2007). İnsanlarda daha yüksek IQ'nun nöropatolojinin gelişimini yavaşlatabilen beyindeki daha yüksek metabolik yeterliği yansıttığı gösterilmiştir (Yeo ve ark., 2011). Yine de, beyin rezervi ve bilişsel rezerv bazı yönlerden bağımsız olmalarına rağmen, beyin patolojisine karşı klinik dayanıklılıktaki bireysel farklılıkları anlamaya bağımsız, ama diğerinin etkisini artıran katkılar sağlarlar.

Bilişsel performans açısından, bilişsel rezerv daha esnek strateji kullanımını, yani yürütücü işlev görevleri ile yüklü bir beceriyi mümkün kılarak yardım edebilir. Bunu desteklemek için, 53-97 yaş aralığında demansı olmayan yaşlılarda yapısal eşitleme modeli uygulanmış ve eğitim yılı, Wide Range Achievement Test (WRAT) puanı ya da İspanyolca konuşanlar için Word Accentuation Test (WAT) puanı ve Peabody Picture Vocabulary Test’in 3. Versiyonunun (PPVT-III) resim sözcük dağarcı̆̆ ölçülerek bilişsel rezervin WAIS-III'ün harf-sayı (LN) sıralama alt ölçeği, tuhaf adam (odd-man-out) görevi ve Color Trails Test'ten elde edilen fark puanı ile ölçülen yürütücü işlevsellikle büyük ölçüde örtüşmüştür (Siedlecki ve ark., 2009). 20-81 yaş arası sağlılı yetişkinlerde, önceden sözü edildiği gibi ölçülen (eğitim, WRAT ve resim sözcük dağarcığı) bilişsel rezervin aynı LN sıralama alt ölçeği ve Wisconsin Card Sorting Test ve Matrix Reasoning Test kullanılarak ölçülen yürütücü işlevsellikle tamamen örtüştüğü bulunmuştur. Bu sonuçlar bilişsel rezervin akıcı yürütücü yetenekleri kapsadığını öne sürer.

Nörogörüntüleme bakımından, bilişsel rezervin normal rezervde ve nöral ödünlemede yansıtıldığ1 düşünülür. Nöral rezerv genç, sağlıklı bireylerin daha yeterli ve daha büyük kapasite ile görevleri yerine getirme yeteneğini verir. Düşük-orta zorlukta görevler için, bilişsel rezervi yüksek olanlar daha az nöral aktivasyon gösterebilirler, çünkü görevi daha fazla nöral yeterlilikle yerine getirebilirler. Tam tersine, görevler yüksek düzeyde zorluk içerdiklerinde, bilişsel rezervi yüksek olanlar daha fazla nöral aktivasyon gösterebilirler, çünkü görevi yerine getirirken kullanacakları daha fazla nöral kapasiteye sahiptirler. Böylece zorluğa dikkat etme gruplar arasındaki nöral aktivasyondaki farklılıkların anlamını anlamada çok önemlidir. Nöral rezerv yaşlanma ve beyin patolojisinin etkilerini azaltmada benzer biçimde iş görür. Nöral rezervi yüksek olanların nöral rezervi daha düşük olanlara göre daha iyi ya da eşit biçimde performans göstermeleri beklenir.

Nöral ödünleme, etkili görev performansı için primer yollardaki bozuklukları ödünlemede sağlıklı genç yetişkinler tarafından sık kullanılmayan değişik beyin bölgelerinin aktivasyonu olarak tanımlanır. Tanımlandığı gibi, daha sonra nöral ödünleme sadece sağlıklı genç yetişkinlerde değil, beyin bozuklukları olanlarda da oluşur. Nöral rezerve gelince, zorluklara dikkat etme nöral ödünlemeyi doğru biçimde belirlemede çok önemlidir. Örneğin, bir bölge yaşlı yetişkinlerde aktif olup daha gençlerde aktif değilse nöral ödünlemeden şüphelenilebilir. Ancak görevin daha zor bir türünde, bölge genç yetişkinler tarafindan aktive edilebilir. Bazen, genç yetişkinler beyin bölgesini kullanmaktalar, ancak beyin aktivasyonunu tanımlamak için seçilmiş istatistiki eşikten dolayı bu durum gözden kaçabilir.

Nöral ödünleme bazen daha kötü performansa eşlik edebilir. Bazı örneklerde, nöral ödünleme, depar atma yeteneğine dönüşmeyecek, ancak bireyin yürümesini mümkün kılan bir baston gibi davranabilir. $\mathrm{Bu}$ metaforun da gösterdiği gibi, nöral ödünleme bazen daha yavaş performansla birliktedir (Zarahn ve ark., 2007; Steffener ve ark., 2009). Nöral ödünlemeyle birlikte, her biri biraz ilave zaman gerektiren beyin bölgeleri boyunca işlemleme yol alır. Başka bir fikir de nöral ödünlemeyle işlemleme primer bir ağdan daha yavaş ikincil bir ağa doğru kayar. Nöral ödünlemenin doğru biçimde hatırlanan daha çok kelimeler açısından daha iyi performansla ilişkili olduğu bulunmuştur (Stern ve ark., 2000). Özetle, nöral ödünleme ya büyütülen ya da küçültülen performansa eşlik eder.

İlave beyin bölgeleri patoloji durumunda aktive olduklarında bu daima ödünlemeyi göstermez, default ağı (varsayılan ağ geçidi) inhibe etme yeteneğinde bir bozukluk (Lustig ve ark., 2003), beyin bölgeleri arasında rekabeti ele almada bozukluklar (Logan ve ark., 2002) ya da duyusal haritaların aynılaşması (bulandırma) (Park ve ark., 2004) gibi zararlı süreçlerden doğduğunda ilave bölgelerin aktivasyonu bozuk işlevli olabilir. Böylece performans kötü olduğunda, nöral ödünleme aktivasyonunu etiketlemeden önce bu zararlı süreçleri çıkarmak gereklidir. 
Nöral ödünlemenin görevden göreve farklılaştığı örtük bir varsayımdır (yani eldeki görevin ortaya çıkan bir özelliğidir). Ancak, bilişsel rezerv geniş bir görevler çeşitliliğinde işlevselliği koruduğunda kapsamlı bir bilişsel rezerv ağı genel bir bilişsel işleve hizmet eder. Bu fikri (Stern ve ark., 2008) destekleyen bazı kanıtlar sonraki bölümde gözden geçirilecektir. Bu doğru ise, bu ağın aktivasyonu nöral ödünlemenin olumlu, yararlı bir biçimini muhtemelen gösterecektir.

\section{Genç, sağlıklı yetişkinlerde bilişsel rezervin nöral belirteçleri}

Stern ve ark. (2003) sözel olmayan bir seriyi tanıma görevini yerine getiren genç yetişkinlerin olayailişkin fMRI analizini yapmışlar, zorlukla aktivasyonu değişen bölgeler aramışlardır. Düşük-zorlukta denemeler hatırlanacak bir şekilden ibaret olmuştur, yüksek-zorlukta denemelerde hatırlanacak şekillerin sayısı \%75 doğruluğa ulaşmak için her bireye göre düzenlenmiştir. Zorlukla birlikte aktivasyondaki değişikliğin bilişsel rezervle birlikte olduğu bölgeleri bulmak için univariate analizler yapılmış, National Adult Reading Test (NART) IQ puanı kullanılmıştır. Hem çalışma hem de test görev evreleri için bölgeler bulunmuştur. Bu sonuçlar bilişsel rezervin sağlıklı genç yetişkinlerde bile ayırt edici göreve-ilişkin aktivasyon (nöral rezerv) ile bağlantılı olduğunu göstermektedir. Göreveilişkin işlemlemedeki bu farklılıklar yaşa ilişkin beyin değişiklikleri ya da patoloji ile özürlü hale geldiklerinde bilişsel rezervi yüksek olanlarda kazanç sağlayabilir.

Önceki veriler multivariate analizler kullanılarak yeniden incelenmiştir (Habeck ve ark., 2003). Bu çalışma için, önce zorlukla aktivasyonu değişen bölgelerin bir ağı aranmıştır. Daha sonra, bu ağın bilişsel rezervin bir işlevi olarak ayırt edici ifade gösterip göstermediği incelenmiştir. İlkin, çalışma evresinde zorluğa-ilişkin ağ bulunmuştur. Bilişsel rezervi daha yüksek bireyler, daha yüksek nöral yeterlilik göstererek bu ağı daha az $\left(\mathrm{r}^{2}=0.24\right)$ ifade etmişlerdir. Daha sonra bu ağın test evresi için ileri doğru uygulanması benzer biçimde bilişsel rezervi daha yüksek olanların daha düşük ağ aktivasyonuna sahip olduklarını bulmuştur $\left(\mathrm{r}^{2}=0.23\right)$. Böylece, bu daha 1lımlı yöntemle de, bilişsel rezervi daha yüksek genç yetişkinler daha büyük nöral etkililik için kanıt sağlamışlardır.

Habeck ve ark. (2005) başka bir görev üzerinde aynı soruyu araştırmışlardır: gecikmiş harf tanıma. Bu görevde, 1,3 ve 6 harflik bellek seti zorluğu oluşturmuştur. Çalışma evresinde, zorluğa-ilişkin ağ NART IQ ile ölçülen bilişsel rezerv ile ilişkili değildir. Maddelerin zihinde aktif biçimde tutulmak zorunda olduğu muhafaza evresinde ya da 7 saniyelik gecikme boyunca zorluğa-ilişkin ağın bilişsel rezervi daha yüksek olanlar tarafından daha az ifade edildiği bulunmuştur $\left(\mathrm{r}^{2}=0.15\right)$. İkinci bir görevde, daha sonra, nöral etkililik muhafaza sırasında bilişsel rezervi daha yüksek genç yetişkinlerde tekrar incelenmiştir.

Bir noktaya kadar, bilişsel rezervi yüksek bireyler daha iyi performans stratejileri kullanmanın bir sonucu olarak daha yüksek nöral etkililiğe sahip olabilirler. Bu fikir strateji kullanımını kontrol ettikten sonra zekayla birlikte olağan nöral etkililik avantajını anlamada başarısız olan bir çalışma ile desteklenir (Toffanin ve ark., 2007). Başka bir destek de, daha fazla aktivasyonun daha fazla strateji deneme ile ilişkili olduğunu bulan bir çalışmadan gelir. Daha yüksek zekası olanların iyi bir stratejiye daha çabucak karar verebildikleri ve sonuç olarak daha az aktivasyon gösterdikleridir (Jaeggi ve ark., 2007).

Gray ve ark. (2003) 3 geri işleyen bellek görevini yerine getiren sağlıklı genç yetişkinleri incelemişlerdir. Çalışmada, olaya-ilişkin aktivasyon Raven'in İleri Progresif Matrisleri ile ölçülen akışkan zekanın bir işlevi olarak farklılaşmıştır. Bu açıkça bilişsel rezerv çalışması olmamasına rağmen, akışkan zekanın bilişsel rezerv için iyi bir temsilci olması beklenir (Siedlecki ve ark., 2009). Yazarlar en zor denemelerdeki aktivasyonun akışkan zekası daha yüksek olanlar için daha yüksek olduğunu bulmuşlardır. Daha yüksek akışkan zeka tuzak denemelerde artmış doğrulukla birliktedir. İlginç biçimde, tuzak olmayan denemelerden tuzak denemelere aktivasyondaki artış \% 99'luk tuzak denemelerdeki zeka-doğruluk ilişkisine aracılık etmiştir. Bu sonuçlar, bilişsel rezervi daha yüksek olanların kullanacakları daha fazla nöral kapasiteye sahip oldukları, görevler zor olduğunda bunun bir avantaj sağladığı fikrini desteklemektedir. 
$\mathrm{Bu}$ çalışmaların bir sınırlılığı kullanılan görevlerin aynı bireylerde çalışan nöral kapasite ve nöral etkililiği görmek için gerekli zorluk aralığına sahip olmayışlarıdır. Genç insanlarda aynı görevde daha yüksek bilişsel rezerv ile çalışan nöral kapasite ve nöral etkililiği anlamak için iyi araştırmalara ihtiyaç vardir.

\section{Sağlıklı genç ve yaşlı yetişkinlerde bilişsel rezervin nöral belirteçleri}

Gençlerle karşılaştırıldığında yaşlılarda bilişsel rezerv ile birlikte olan nöral aktivasyon bazen aynıdır, ama değișebilir de. Scarmeas ve ark. (2003b) sözel olmayan dizi tanıma görevi üzerinde sağlıklı genç ve yaşlıların PET aktivasyonunu incelemişler, bilişsel rezerv eğitim yılı, NART ve yaşa göre ölçeklenmiş sözcük dağarcığı puanlarından oluşturulmuş bir faktör puanı ile ölçülmüştür. Düşükzorluk koşulu tek bir şekilken, yüksek-zorluk koşulu \% 75 doğruluğa ulaşsınlar diye her katılimcıya göre uyarlanmıştı. Her grup için ayrı ayrı bilişsel rezerv ile ilişkili bölgeleri bulmak ve daha sonra genç ve yaşlılar arasında bilişsel rezerv ile farklı biçimde ilişkili bölgeleri bulmak için univariate analizler kullanılmıştır. İlk analizler sadece gençler için bilişsel rezerv ile ilişkili bazı bölgeler ve yalnızca yaşlılar için bilişsel rezerv ile ilişkili diğer bölgeleri bulmuştur. İkinci analizler iki grup arasında üç farklı ifade tipini bulmuştur: bazı bölgeler gençlerde daha yüksek bilişsel rezerv ile pozitif olarak ifade edilmiştir ve yaşlılarda daha yüksek bilişsel rezerv ile negatif olarak ifade edilmiştir; bazı bölgeler tam tersi bir örüntü göstermiştir; ve bazı bölgeler gençlerde bilişsel rezerv ile pozitif olarak ifade edilmiştir ve yaşlilarda bilişsel rezerv pozitif olarak ama yine de hafif biçimde ifade edilmiştir. Bilişsel rezervin ifade edilişindeki gençler ve yaşlılar arasındaki bu farklılıklar ödünleyici yeniden organizasyonun yaşlanmayla birlikte olduğunu göstermektedir.

Stern ve ark. (2005) zorluk ve yaşla birlikte ayırt edici biçimde aktive edilmiş olan bölgeleri bulmak için verileri multivariate analizlerle yeniden incelemişlerdir. Genç ve yaşlı bireyler arasında farklı biçimde aktive olmuş beyin bölgelerinin bir ağını bulmuşlardır. Bu ağın ifadesi daha yüksek nöral etkililik göstererek gençlerde bilişsel rezerv ile pozitif olarak ilişkili $\left(r^{2}=0.45\right)$ ve daha yüksek nöral kapasite göstererek yaşlılarda bilişsel rezerv ile olumsuz olarak ilişkili olmuştur $\left(r^{2}=-0.50\right)$. Özetle, genç ve yaşlılar bilişsel rezerv örüntülerini ters biçimde göstermişlerdir. Yazarlar bu farkın yaşlanmada ya da nöral ödünlemede beyin ağlarının yararlı yeniden organizasyonu yansıttı̆̆ını ileri sürmektedirler.

Stern ve ark. (2008) daha sonra genç ve yaşlı yetişkinlerde farklı görevlerde bilişsel rezervin benzer biçimde çalışıp çalışmadığını incelemişlerdir. Olaya-ilişkin fMRI iki farklı görev tarafindan paylaşılan bilişsel-rezerve-ilişkin ağı incelemede kullanılmıştır: gecikmiş harf ve şekil Sternberg. Bilişsel rezerv NART ve WAIS-R'ın sözcük dağarcığı alt ölçeğiyle ölçülmüştür. Harf görevi 1, 3 ve 6 harflik zorluk düzeylerinden oluşurken, şekil görevi 1, 2 ve 3 şekillik zorluk düzeylerinden oluşmuştur. Genel olarak, şekil görevi harf görevine göre ciddi biçimde daha zorlayıcı olmuştur. Çalışma evresi için iki ağ bulunmuştur. İlk ağ yalnızca harf görevi sırasında, ikinci ağ hem harf hem de şekil görevleri sırasında kullanılmıştır. Genç bireyler için, her iki görevdeki ağ aktivasyonu bilişsel rezerv ile olumsuz olarak ilişkili olup daha fazla bilişsel rezervi olanlarda nöral etkililik daha yüksek olmuştur. Yaşlı bireyler için, yalnızca daha az zorlayıcı harf görevi için bilişsel rezerv ile ağ ifadesi olumsuz olarak ilişkili olmuştur. Bu sonuçlar birçok görevi yerine getirirken yararlanılabilen genel bir "bilişsel rezerv ă̆ı"nı ileri sürmektedir. Bu durum bilişsel rezervin birçok farklı görevler ve gerçek-dünya işlevleri için beyin patolojisine karşı yarar sağladığı gözlemiyle uyumludur.

Steffener ve ark. (2005) gecikmiş harf tanıma görevini yerine getiren genç ve yaşlı bireyler arasındaki olaya-ilişkin fMRI aktivasyonunu incelemişlerdir. 1, 3 ve 6 harflik bellek seti 3 zorluk düzeyinden oluşmuş; muhafaza sırasında artan zorlukla birlikte ifadenin değiştiği ağlar bulunmuştur. Genç yetişkinler tek bir ağdan yararlanırken, yaşlılar ilave bir ağla birlikte bu ağdan yararlanmışlardır. Yaşlilarda temel ağdaki daha fazla patolojinin, presentral girustaki daha fazla atrofiyi harekete geçirerek, ikincil ağın daha fazla kullanımıyla birlikte olduğunu göstermişlerdir. Genç bireyler ikincil ağı kullanmadıkları için yaşılılarda nöral ödünlemeyi yansıttığı varsayılabilir. Önemli olan, daha fazla 
bilişsel rezervi olan yaşlıların ikincil ağı çalıştırmadan önce daha fazla patolojiyi tolere edebilmiş olduklarıdır.

\section{Sağlıklı yaşılılar ve Alzheimer hastalarında bilişsel rezervin nöral belirteçleri}

Scarmeas ve ark. (2004) sözel olmayan dizi tanıma görevini yerine getirirken sağlıklı yaşlılar ve Alzheimer hastalarında PET aktivasyonunu incelediler. Düşük-zorluk koşulu tek bir şekili içerirken, yüksek-zorluk koşulu her katılımc1 \% 75 doğruluğa ulaşabilsin diye uyarlanmıştır; bilişsel rezerv eğitim y1lı, NART IQ ve WAIS-R'1n sözcük dağarcığı alt ölçeğinden olușturulmuş bir faktör puanı kullanılarak ölçülmüştür. Aktivasyon örüntüleri sağlıklı yaşlılar ve Alzheimer hastaları arasında farklılaşmıştır. Bazı bölgelerde, yüksek bilişsel rezervi olan Alzheimer hastaları daha fazla aktivasyon gösterirken, daha yüksek bilişsel rezervi olan sağlıklı yaşlılar daha az aktivasyon göstermişlerdir, bazı bölgelerde de ilişki tersine dönmüştür. Bu bölgeye-özgü farklılıklar Alzheimer hastalarında beyin ağlarının ödünleyici yeniden organizasyonunu yansıtmıştır.

Solé-Padullés ve ark. (2009) sağlıklı yaşlı, hafif bilişsel bozukluk ve Alzheimer hastaları arasında tanıma görevi üzerinde bilişsel-rezerve ilişkin fMRI aktivasyonunu karşılaştırmışlardır. Uyaranlar manzara ve dışarıda eylemde bulunan insan imgeleridir; bilişsel rezerv WAIS-III'ün sözcük dağarcığ alt ölçeği, bir eğitim-meslek ölçeği ve boş zaman aktivitelerine katılım ölçeğinden oluşan bir puanla ölçülmüsştür. Gruplar arasındaki ayırt edici performans için uyumdan sonra univariate analizler yapılmıştır. Sağlıklı yaşlılarda, daha fazla bilişsel rezerv daha az aktivasyonla ilişkilidir, daha yüksek nöral etkililik göstermiştir. Tersine, hafif bilişsel bozukluk ve Alzheimer hastalığında daha fazla nöral kapasite gösterdikleri düşünülerek daha çok bilişsel rezervi olanlar daha fazla aktivasyon göstermişlerdir. Bir önceki çalışmayla birlikte ele alındığında, ters bilişsel-rezerve ilişkin beyin aktivasyonu sağlıklı ve hasta yaşlı bireyler arasında görülür.

\section{Bilişsel rezervin tanı ve önlemede doğurguları}

İşlevsel sonuçları olmaksızın patoloji var olabildiğinden dolayı, daha fazla bilişsel rezervi olan bireyler tanıda zorluk yaratırlar. Üstelik, klinik ciddiyetin herhangi bir evresindeki demansli hastalarda, daha fazla bilişsel rezervi olan bireyler daha çok ileri patolojiye sahip olacaklardır. Nörogörüntüleme biyobelirteçleri, klinik sonuçlardan önce bile, Alzheimer patolojisinin erken taranmasına yardım etmek için geliştirilmektedir. Daha fazla bilişsel rezervi olan bireyler kortikal kalınlıkta daha çok azalmaları (Querbes ve ark., 2009), beyin omurilik sıvısında (Shaw ve ark., 2009) ve plazmada (Yaffee ve ark., 2011) amiloid peptid düzeylerini ve daha fazla bölgesel atrofiyi (Hua ve ark., 2008), klinik sonuçlar ortaya çıkmadan önce, tolere eder. Bu nedenlerle, modele bilişsel rezerv değişkenlerini ekleyerek biyobelirteçlerin yordayıcı doğruluğu arttırılır (Roe ve ark., 2011). Daha da genel olarak, hem altta yatan patoloji hem de bilişsel rezerv hesaba katıldığında, klinik durum daha iyi anlaşılabilir.

Yaşlı nüfusun gelecekteki artışıyla birlikte, müdahaleler uygulanmazsa demans vakalarının sayısı 2050 yılına kadar 3 katına katlayacaktır (Hebert ve ark., 2003). Katzman (1993) daha yüksek eğitim 5 yılda Alzheimer hastalığını bertaraf edeceğinden, prevalansının ciddi biçimde düşebileceği sonucuna varmıştır. Böylece bilişsel rezerv müdahaleleri bu hastalığı önlemede temel bir nonfarmakolojik yaklaşımı oluşturabilir (Stern, 2006). Alzheimer hastalığının büyük bir genetik komponenti olmasına rağmen (Gatz ve ark., 2006), davranışsal ve çevresel faktörler başlangıç zamanı ve ifadesi üzerinde hala önemli bir etkiye sahiptir. Geç başlangıçlı Alzheimer hastalığındakine göre daha güçlü genetik komponenti olan erken başlangıçlı Alzheimer hastalığında bile bilişsel rezervin koruyucu bir rol oynadığ gösterilmiştir (Fairjones ve ark., 2011). Gelecek çalışmalar Alzheimer hastalığ ve diğer yaşa bağlı hastalıkları önlemek ya da geciktirmek için bilişsel rezervi arttırıcı stratejileri açıklayabilir. 